\title{
THE FALL IN RECTAL TEMPERATURE SEEN BEFORE PARTURITION IN SHEEP
}

\author{
R. EWBANK \\ Faculty of Veterinary Science, University of Liverpool
}

(Received 4th March 1969)

\begin{abstract}
Summary. In the pregnant ewe, there is a general decline in rectal temperature of the order of $0.7^{\circ} \mathrm{C}$ over the $54 \mathrm{hr}$ before parturition. Individual variation, however, makes this temperature drop unreliable for the prediction of the possible time of onset of lambing.
\end{abstract}

Several of the domesticated animals show a slight rise in body temperature in late pregnancy and a temperature decline in the period just before parturition (Weisz, 1943). In cattle (Ewbank, 1963), this drop measures some $0.6^{\circ} \mathrm{C}$ and commences, on average, $54 \mathrm{hr}$ before calving: the large variation in readings about this average, however, makes it impossible to use the temperature drop for a reliable prediction of the possible time of parturition. It has been shown (Ewbank, 1963) that the healthy cow, even when exhibiting external signs of imminent parturition, such as mammary distension, relaxation of the sacrosciatic ligaments and vulval enlargement, is unlikely to calve within the succeeding $12 \mathrm{hr}$ if its rectal temperature is above $38.8^{\circ} \mathrm{C}$, the normal temperature being $38 \cdot 5^{\circ} \mathrm{C}$.

While a similar technique has less application in sheep than in cattle husbandry, any reliable method of indicating the imminence or otherwise of parturition would have value in appropriate research programmes.

Few investigators have studied the temperature of the ewe around the time of parturition although McKenzie \& Bogart (1934) give the average body temperature of ewes for the 2 days before and the 7 days after lambing as $39.4^{\circ} \mathrm{C}$; Hafez, Badreldin \& Sharafeldin (1956) found that pregnancy has no effect upon the body temperatures of Egyptian fat-tailed sheep; and Roberts (1964) briefly reported (without quoting results obtained) that the deep vaginal temperature has little practical value in predicting the time of onset of parturition. One factor affecting body temperature is rate of heat loss and it is of interest that Brockway, McDonald \& Pullar (1963) reported an increase in heat loss to the environment for sheep during the last $24 \mathrm{hr}$ of pregnancy.

In the present investigation, twelve Clun Forest ewes due to lamb in early March were trained to stand quietly in yolk type head holders and to allow the insertion of a clinical thermometer (N.P.L. certified, $\frac{1}{2}-\min$ reading) $8 \mathrm{~cm}$ into the rectum for approximately $1 \mathrm{~min}$. Temperature readings could be taken to an accuracy of $\pm 0.05^{\circ} \mathrm{C}$. The animals were allowed outside during the day and kept overnight under an open-sided barn. Temperatures were recorded from 
10 days before the expected date of the first lambing. Eleven of the ewes lambed down over a period of 17 days and delivered live offspring; one ewe was withdrawn from the group due to pregnancy toxaemia. The temperature of each ewe was taken each day, once between 09.00 and 10.00 hours (B.S.T.) and once again between 21.00 and 22.00 hours. Mendel \& Raghavan (1964) in their study of the diurnal variation in sheep body temperatures indicate that there is normally only a difference of about $0.05^{\circ} \mathrm{C}$ between the rectal temperatures recorded at these times in any one sheep.

Ten of the eleven lambings occurred between 10.00 and 21.00 hours and in six of these, the approximate hour of birth was known. The mean time for this was $5 \mathrm{hr}$ after the morning temperature-taking session.

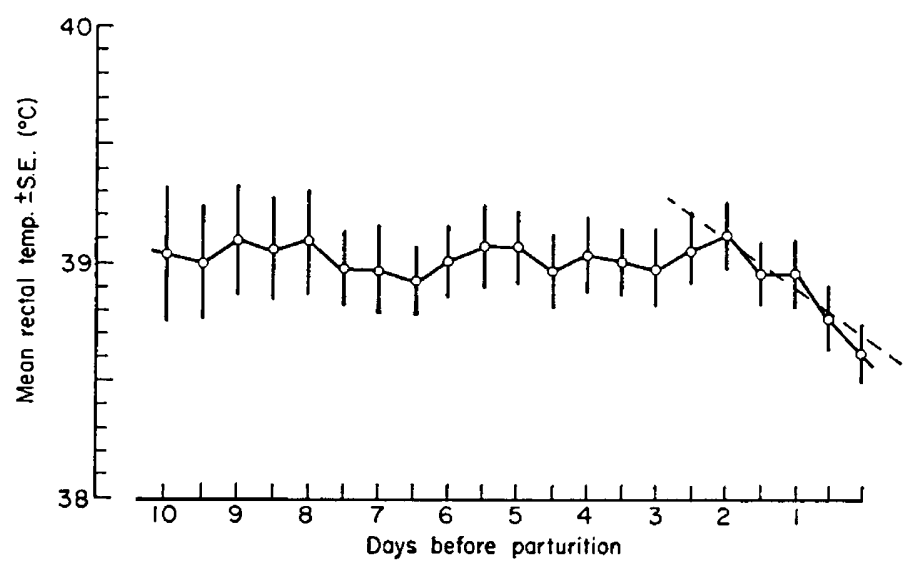

TEXT-riG. 1. Mean rectal temperature for the 10 days before parturition.

The results are presented as if lambing occurred midway between the recording sessions, i.e. $6 \mathrm{hr}$ after the last temperature record.

In the Text-figure the mean rectal temperatures and their standard errors have been plotted against time before parturition. A linear regression line equation, $\mathrm{Y}=39 \cdot 160-0.009 \mathrm{X}$, can be drawn through the five terminal means. The fit of the regression line to these means is highly significant $(t$-test applied to sample standard deviation of the regression coefficient-Snedecor \& Cochran, 1967).

The mean value of rectal temperature over the period 2 to 10 days before lambing is $39.0 \pm 0.04(\text { S.E. })^{\circ}$ C. This is somewhat lower than the average value given for the periparturient ewe by McKenzie \& Bogart (1934), although their mean will be dominated by the postparturient readings, and is also less than the figures of 39.2 to $39.4^{\circ} \mathrm{C}$ given as the normal temperature of the sheep by Blood \& Henderson (1968), Miller \& Robertson (1959) and Belschner (1965).

It can be seen that, for the $54 \mathrm{hr}$ before lambing, there appears to be a consistent temperature drop away from the values recorded over the previous 9 days. Individual variations of temperature about these times, however, made it impossible to select any particular temperature or temperature change as a 
prediction point for the imminence or otherwise of lambing. This finding is in general agreement with the conclusions of Roberts (1964). The duration of the temperature drop overlaps the period of increased heat loss described by Brockway et al. (1963).

\section{REFERENCES}

BeLschner, H. G. (1965) Sheep management and diseases, 8th edn, p. 767. Angus \& Robertson, Sydney. Blood, D. C. \& Henderson, J. A. (1968) Veterinary medicine, 3rd edn, p. 13. Baillière, Tindall \& Cassell, London.

Brockway, J. M., McDonald, J. D. \& Pullar, J. D. (1963) The energy cost of reproduction in sheep. 7. Physiol., Lond. 167, 318.

Ewbank, R. (1963) Predicting the time of parturition in the normal cow: a study of the precalving drop in body temperature in relation to the external signs of imminent calving. Vet. Rec. 75, 367.

Hafez, E. S. E., Badreidin, A. L. \& Sharapeidin, M. A. (1956) Heat-tolerance studies of fat-tailed sheep in the sub tropics. F. agric. Sci., Camb. 47, 280.

McKenzie, F. F. \& Bogart, R. (1934) Observations on ewes at the time of parturition. Bull. Unio. Mo. agric. Exp. Stn, 340, 10.

Mendel, V. E. \& Raghavan, G. V. (1964) A study of diurnal temperature patterns in sheep. $\mathcal{F}$. Physiol., Lond. 174, 206.

Mirler, W. C. \& Robertson, E. D. S. (1959) Practical animal husbandry, 7th edn, p. 116. Oliver \& Boyd, Edinburgh and London.

Roberts, S. J. (1964) Report of the New York State Veterinary College at Cornell University for the year $1962-63$, p. 93.

SNedecor, G. W. \& Cochran, W. G. (1967) Statistical methods, 6th edn, p. 138. Iowa State University Press, Ames.

WEIsz, L. (1943) The temperature phenomenon before parturition and its clinical importance. $\mathcal{F}$. Am. vet. med. Ass. 102, 123. 